\title{
HUBUNGAN KUNJUNGAN ANTENATAL CARE DENGAN KEJADIAN ANEMIA PADA IBU HAMIL
}

\author{
Ditya Yankusuma Setiani ${ }^{1}$, Anisa Galih Pratiwi ${ }^{2}$
}

\begin{abstract}
Background: Anemia in pregnancy is a decrease in hemoglobin levels occurring during pregnancy due to iron deficiency or folate deficiency. In Sukoharjo Regency in 2013 the number of pregnant women reached 14,966 people, and pregnant women suffering from anemia were 1,031 people or $6.8 \%$ of the number of pregnant women. The results of a preliminary study conducted in the Tawangsari Village Midwife found 10 people who had anemia. At the interview with 10 pregnant women, 3 answered saying they were not regular in carrying out pregnancy examinations. Purpose and benefit: To determine the relationship between antenatal care and the incidence of anemia in pregnant women in Pranan Village. The benefit of research is to develop and add to existing knowledge about the relationship between antenatal care visits and the incidence of anemia.

The subject of study: 32 third trimester pregnant women in Pranan Village

Method The research: Used descriptive analytic method with cross sectional approach. This study to determine the factors associated with the incidence of anemia in pregnant women. Sampling in total sampling. The data obtained were analyzed by Chi Square test with $p=0.05$. The Result of Research: The study used a method using cross sectional. This study was to determine the relationship between antenatal care visits and the incidence of anemia. Sampling in total sampling. The data obtained were analyzed by Chi Square test with $p=0.05$. Conclusion: There was no association between antenatal care visits and the incidence of anemia.
\end{abstract}

Keywords: Anemia, Pregnant Women, Antenatal Care Visits

\section{PENDAHULUAN}

Anemia adalah keadaan dimana kadar hemoglobin di bawah nilai normal. Anemia pada kehamilan adalah penurunan kadar hemoglobin yang terjadi selama kehamilan karena kekurangan zat besi atau kekurangan folat. Hal ini disebabkan oleh ekspansi volume plasma yang relatif lebih besar jika dibandingkan dengan peningkatan massa hemoglobin dan volume sel darah merah yang menyertai kehamilan normal (Leveno, ed., 2016).

Berdasarkan hasil Riset Kesehatan Dasar (Riskesdas) tahun 2013, prevalensi anemia pada ibu hamil di Indonesia sebesar $37,1 \%$. Pemberian tablet $\mathrm{Fe}$ di Indonesia pada tahun 2012 sebesar 85\%. Persentase ini mengalami peningkatan dibandingkan pada tahun 2011 yang sebesar 83,3\%.
Meskipun pemerintah $\begin{array}{r}\text { sudah } \\ \text { melakukan }\end{array}$
program penanggulangan anemia dengan memberikan 90 tablet Fe kepada ibu hamil selama periode tertentu dengan tujuan menurunkan angka anemia ibu hamil, tetapi kejadian anemia masih tinggi (Kementerian Kesehatan RI, 2013).

Di Kabupaten Sukoharjo pada tahun 2013 jumlah ibu hamil mencapai 14.966 jiwa, dan ibu hamil yang menderita anemia sebanyak 1,031 jiwa atau $6,8 \%$ dari jumlah ibu hamil (Dinas Kesehatan Sukoharjo, 2013). Anemia pada ibu hamil dapat disebabkan oleh beberapa faktor yaitu asupan zat besi yang kurang, kurangnya asupan bahan pangan yang mengandung folat dan zat besi, kurang terpaparnya informasi tentang bahaya anemia pada ibu hamil serta pemeriksaan Antenatal 
Care (ANC) yang tidak lengkap atau tidak teratur.

Penelitian yang dilakukan oleh Hendrayani, Sawitri dan Karmaya (2013), tentang perilaku pemeriksaan antenatal sebagai faktor risiko anemia gizi ibu hamil di Puskesmas II Denpasar Selatan tahun 2012 dengan responden sebanyak 69 ibu sebagai kelompok kasus dan 69 ibu sebagai kelompok kontrol. Pada penelitian tersebut didapatkan hasil bahwa frekuensi dan waktu ANC yang tidak memadai memiliki risiko 23,29 kali lebih besar terhadap kejadian anemia $(95 \% \mathrm{Cl}$ 7,49-72,33) dibandingkan dengan frekuensi serta waktu ANC yang memadai.

Perawatan antenatal (antenatal care) adalah asuhan yang diberikan oleh perawat atau tenaga medis mulai dari konsepsi sampai persalinan, asuhan diberikan berdasarkan keadaan fisik, emosional dan sosial ibu, janin, pasangan, serta anggota keluarga dengan tujuan untuk mengurangi penyulit - penyulit di masa antepartum yang salah satunya adalah anemia pada ibu hamil (Hutahaean, 2013). Anemia pada kehamilan dapat beresiko untuk terjadinya abortus, partus prematurus, partus lama karena intertia uteri, perdarahan postpartum karena atonia uteri, shock, infeksi, baik intrapartum maupun post partum dan anemia yang sangat berat dengan $\mathrm{Hb}$ kurang dari $4 \mathrm{~g} / 100 \mathrm{ml}$ dapat menyebabkan dekompensasi kordis (Wagiyo dan Putrono, 2016).

Wanita hamil memerlukan sedikitnya empat kali kunjungan selama periode antenatal yaitu pada kehamilan trimester pertama $(<14$ minggu), kehamilan trimester kedua (14-28 minggu), kehamilan trimester ketiga (28-36 minggu) dan sesudah minggu ke 36 (Kumalasari, 2015).

Penelitian yang dilakukan oleh Wibowo dan Wisnuwijoyo (2014), mengenai survei cepat karakteristik dan prevalensi anemia ibu hamil di Kabupaten Sukoharjo tahun 2011 dengan responden adalah seluruh ibu hamil yang bertempat tinggal tetap di Kabupaten Sukoharjo yang berjumlah 240 responden, didapatkan hasil bahwa prevalensi anemia ibu hamil sebesar 51,3\% yang terdiri dari $7,5 \%$ anemia sedang dan 43,8 \% anemia ringan. Hasil penelitian juga didapatkan bahwa masih terdapat ibu hamil yang tidak teratur dalam melakukan kunjungan antenatal care yaitu $<4$ kali kunjungan sebesar $34,2 \%$.

Penelitian yang dilakukan oleh Shitie, Zewde dan Molla (2018), tentang Anemia and Other Hematological Profiles of Pregnant Woman Attending Antenatal Care in Debre Berhan Referral Hospital, North Shoa, Ethiopia, didapatkan hasil bahwa prevalensi anemia sebesar 2,8\% (8 responden) dari total populasi yaitu 284 responden. Ibu hamil dengan anemia ringan sebesar $62,5 \%$ dan anemia berat $25 \%$. Penyebab anemia pada ibu hamil tersebut dikaitkan dengan keteraturan ibu mengunjungi klinik antenatal, pada ibu yang mengunjungi klinik antenatal kurang dari tiga kali beresiko dua kali lebih tinggi terkena anemia dibandingkan ibu yang mengunjungi klinik antenatal sebanyak tiga kali atau lebih.

Hasil dari studi pendahuluan yang dilakukan di Bidan Desa ditemukan sebanyak 10 orang ibu hamil yang mengalami anemia. Pada saat wawancara dengan 10 ibu hamil, 3 diantaranya mengatakan tidak teratur dalam melakukan pemeriksaan kehamilan.

Penelitian ini akan meneliti tentang keterkaitan antara ANC dengan kejadian anemia dan jika penelitian ini tidak dilakukan maka akan beresiko terhadap kondisi kesehatan ibu dan janin. Berdasarkan latar belakang 
masalah di atas maka peneliti tertarik untuk melakukan penelitian tentang "Hubungan Kunjungan Antenatal Care dengan Kejadian Anemia pada lbu Hamil di Kelurahan Pranan Kecamatan Polokarto".

\section{TUJUAN PENELITIAN}

Tujuan umum penelitian untuk mengetahui hubungan antara kunjungan antenatal care dengan kejadian Anemia pada Ibu Hamil di Kelurahan Pranan Kecamatan Polokarto, dan tujuan khusus untuk untuk mengetahui gambaran kejadian anemia dan kunjungan antenatal care pada ibu hamil di desa Pranan.

\section{METODE/DESAIN PENELITIAN}

Penelitian ini menggunakan metode korelasi dengan pendekatan cross sectional. Penelitian ini untuk mengetahui hubungan kunjungan antenatal care dengan kejadian anemia.

Pengumpulan data dengan cara penyebaran angket dan menggunakan hasil laboratorium serta data yang sudah terkumpul dianalisa menggunakan Uji ChiSquare dengan program SPSS seri 18.0

\section{POPULASI, SAMPEL DAN TEKNIK SAMPLING}

Subyek penelitian adalah ibu hamil trimester III di Desa Pranan Sukoharjo yang berjumlah 32 responden. Dalam penelitian ini peneliti menggunakan teknik total sampling.

\section{HASIL PENELITIAN}

Berdasarkan penelitian yang telah dilakukan didapatkan karakteristik responden sebagai berikut :
Tabel 1.

Distribusi Frekuensi

Karakteristik Responden

\begin{tabular}{ccc}
\hline $\begin{array}{c}\text { Karakteristik } \\
\text { Responden }\end{array}$ & $\mathrm{F}$ & $\%$ \\
\hline Umur lbu (th) & & \\
$<20$ & 1 & 3,1 \\
$20-30$ & 16 & 50 \\
$>30$ & 15 & 46,9 \\
Pendidikan & & \\
Tinggi & 28 & 87,5 \\
Rendah & 4 & 12,5 \\
Penghasilan & & \\
Rendah & 7 & 21,9 \\
Sedang & 22 & 68,7 \\
Tinggi & 3 & 9,4 \\
Jarak Kehamilan & & \\
Dekat & 4 & 12,5 \\
Jauh & 18 & 56,2 \\
Anak pertama & 10 & 31,3 \\
Konsumsi Zat & & \\
Besi & & \\
Rutin & 30 & 93,7 \\
Tidak Rutin & 2 & 6,3 \\
Merokok & & \\
Ya & 0 & 0 \\
Tidak & 32 & 100 \\
Paparan Asap & & \\
Rokok & & 75 \\
Ya & 24 & 25 \\
Tidak & 8 & \\
\hline & &
\end{tabular}

Dari Tabel 1 di atas diperoleh informasi bahwa jumlah responden pada kelompok umur $<20$ tahun paling kecil yaitu 1 responden $(3,1 \%)$, sedangkan mayoritas responden berada pada usia 20-30 tahun yaitu 16 responden (50\%) dan Mayoritas responden mempunyai tingkat pendidikan tinggi yaitu 28 responden $(87,5 \%)$ sedangkan responden dengan pendidikan rendah ada 4 responden (12,5\%). Mayoritas penghasilan dari anggota keluarga sedang yaitu 22 responden $(68,7 \%)$, jarak kehamilan mayoritas jauh yaitu 18 responden (56,2\%), mayoritas kebiasaan konsumsi tablet besi sudah rutin yaitu 30 responden $(93,7 \%)$ dan $100 \%$ responden tidak merokok akan 
tetapi 24 responden $(75 \%)$ responden terpapar asap rokok setiap harinya.

Tabel 2.

Distribusi Frekuensi Kunjungan ANC dan Kejadian Anemia

\begin{tabular}{llcc}
\hline Variabel & Kategori & $\mathrm{f}$ & $\%$ \\
\hline Anemia & Anemia & 30 & 93,7 \\
& Tidak & 2 & 6,3 \\
Kunjungan & Anemia & & \\
ANC & Teratur & 22 & 68,7 \\
& Tidak & 10 & 31,3 \\
\hline
\end{tabular}

Dari Tabel 2 di atas dapat dicermati bahwa jumlah responden yang mengalami anemia lebih banyak yaitu 30 responden $(93,7 \%)$ dan yang tidak mengalami anemia adalah 2 responden $(6,3 \%)$. Mayoritas responden teratur dalam melakukan kunjungan ANC yaitu 22 $(68,7 \%)$ dan 10 responden $(31,3 \%)$ tidak teratur dalam melakukan kunjungan ANC.

Tabel 3

Tabulasi Silang Kunjungan ANC dengan Kejadian Anemia

\begin{tabular}{lcccc}
\hline \multirow{2}{*}{$\begin{array}{c}\text { Kejadian } \\
\text { Anemia }\end{array}$} & \multicolumn{2}{c}{ Kunjungan ANC } & & \\
\cline { 2 - 3 } & $\begin{array}{c}\text { Teratur } \\
(\%)\end{array}$ & $\begin{array}{c}\text { Tidak } \\
\text { Teratur } \\
(\%)\end{array}$ & & \\
\hline Tidak & 2 & 0 & 2 & \\
Anemia & $(6,25)$ & $(0)$ & $(6,25)$ & 0,325 \\
Anemia & 20 & 10 & 30 & \\
& $(62,5)$ & $(31,25)$ & $(93,75)$ & \\
\hline Total & 22 & 10 & 32 & \\
& $(68,75)$ & $(31,25)$ & $(100)$ & \\
\hline
\end{tabular}

Dari hasil uji Chi-Square program SPSS versi 18.0 dengan $\alpha=5 \%$ (0.05) diperoleh $p$ sebesar 0.325 sehingga nilai $p>0.05$, yang berarti Ho diterima dan $\mathrm{H}_{\mathrm{a}}$ ditolak, hal ini menunjukkan bahwa tidak ada hubungan antara kunjungan antenatal care dengan kejadian anemia pada lbu hamil di Desa Pranan.

\section{PEMBAHASAN}

Berdasarkan hasil penelitian pada 32 ibu hamil di Desa Pranan didapatkan bahwa 30 responden $(97,3 \%)$ mengalami anemia sedangkan 2 responden (6,3\%) tidak mengalami anemia. Anemia pada ibu hamil terjadi karena penurunan kadar hemoglobin selama kehamilan yang disebabkan karena kekurangan zat besi dan folat. Hal ini terjadi karena ekspansi volume plasma yang relatif lebih besar jika dibandingkan dengan peningkatan massa hemoglobin dan volume sel darah merah yang menyertai kehamilan normal (Leveno, ed. 2016). Pada penelitian Wibowo dan Wisnuwijoyo (2014), survei cepat tentang kejadian anemia pada ibu hamil didapatkan hasil bahwa sebesar $51,3 \%$ ibu hamil mengalami anemia dan diduga karena jumlah kelahiran yang terlalu banyak, ANC belum maksimal dan ketidakteraturan ibu hamil dalam minum tablet besi. Resiko yang dapat terjadi pada ibu hamil yang mengalami anemia adalah abortus, partus prematurus, partus lama karena inersia uteri, perdarahan post partum karena atonia uteri, syok, infeksi baik intra partum maupun post partum (Wagiyo dan Putrono, 2016).

Pemeriksaan ANC perlu dilakukan secara lengkap dan teratur untuk memantau kondisi ibu dan janin. Dengan frekuensi minimal 4 kali kunjungan selama kehamilan, kontak pertama kali selambatlambatnya pada kehamilan 12 minggu meningkatkan upaya dilakukan tindakan yang tepat untuk menghindari berbagai faktor risiko baik ibu ataupun janinnya. Berdasarkan hasil penelitian, didapatkan hasil bahwa dari 32 ibu hamil, 22 responden teratur melakukan ANC dan 10 responden tidak teratur melakukan ANC. Hasil survei yang didapatkan, bahwa dari 22 responden yang teratur 
melakukan ANC, 21 responden sudah pernah mendapatkan informasi dari tenaga kesehatan tentang pentingnya melakukan pemeriksaan kehamilan dan hanya 1 responden yang tidak mendapatkan informasi. Sebagaimana penelitian yang dilakukan oleh Armaya (2018), bahwa ada hubungan antara tingkat pengetahuan ( $p=0,003)$, sikap $(p=0,016)$, dukungan petugas kesehatan $(p=0,021)$ dan dukungan keluarga $(p=0,022)$ dengan kepatuhan ibu hamil dalam melakukan kunjungan ANC di Puskesmas Kota Kutacane Aceh Tenggara, artinya bahwa ada hubungan tingkat pengetahuan, sikap, dukungan petugas kesehatan dan dukungan keluarga dengan kepatuhan ibu hamil melakukan kunjungan ANC. Menurut Walyani dan Purwoastuti (2015), perawatan kehamilan merupakan salah satu faktor yang amat sangat perlu diperhatikan untuk mencegah terjadinya komplikasi dan kematian ketika persalinan, disamping itu juga untuk menjaga pertumbuhan dan kesehatan janin. Memahami perilaku perawatan kehamilan (antenatal care) adalah penting untuk mengetahui dampak kesehatan bayi dan ibu sendiri. Fakta berbagai kalangan masyarakat di Indonesia, masih banyak ibu-ibu yang menganggap kehamilan sebagai hal yang biasa, alamiah, dan kodrati. Mereka merasa tidak perlu memeriksakan dirinya secara rutin ke bidan ataupun dokter. Masih banyaknya ibu-ibu yang kurang menyadari pentingnya pemeriksaan kehamilan menyebabkan tidak terdeteksinya faktor-faktor resiko tinggi yang mungkin dialami oleh mereka. Resiko ini baru diketahui pada saat persalinan yang sering kali karena kasusnya sudah terlambat dapat membawa akibat fatal yaitu kematian.
Hasil uji korelasi dengan Chi-Square diperoleh $p$-value sebesar 0.325 yang menunjukkan bahwa tidak ada hubungan antara kunjungan antenatal care dengan kejadian anemia pada lbu hamil di Desa Pranan. Faktor penyebab anemia tidak hanya karena keteraturan kunjungan antenatal care saja melainkan masih banyak faktor yang mempengaruhi kejadian anemia, seperti status ekonomi, ras, merokok, lingkungan, kepatuhan konsumsi tablet besi, jarak kehamilan dan kurang terpaparnya informasi tentang bahaya anemia pada ibu hamil (Varney, Kriebs dan Gegor, 2007). Pada hasil penelitian ini penyebab anemia pada ibu hamil diduga karena paparan asap rokok. Hasil survei didapatkan bahwa walaupun responden tidak merokok secara aktif, tapi masih ditemukan bahwa 24 (75\%) responden masih terpapar asap rokok dari suaminya. Kandungan yang terdapat dalam rokok yaitu tar, karbon monoksida dan nikotin dapat mengakibatkan terjadinya kompetisi untuk tempat mengikat oksigen pada sel darah merah yang mengakibatkan anemia pada ibu hamil (Varney, Kriebs dan Gegor, 2007). Teori ini dibuktikan pada penelitian Safitri dan Syahrul (2015), dimana didapatkan hasil bahwa paparan asap rokok meningkatkan risiko kejadian anemia pada ibu hamil dengan OR 4,09 yang artinya ibu hamil yang terpapar asap rokok mempunyai risiko sebesar 4,09 kali mengalami anemia dibanding ibu hamil yang tidak terpapar asap rokok.

Hasil penelitian ini berbeda dengan penelitian yang dilakukan oleh Purwandari, Lumy dan Polak (2016), didapatkan hasil bahwa ada hubungan antara paritas $(p=0,005)$, umur $(p=0,002)$, kunjungan ANC ( $p$ $=0,013$ ), dan konsumsi tablet besi $(p=0,004)$ dengan kejadian anemia pada lbu hamil di Puskesmas Tonsea Minahasa, artinya paritas, 
umur, kunjungan ANC dan konsumsi tablet besi berhubungan dengan kejadian anemia pada ibu hamil. Pada penelitian ini, kunjungan ANC berhubungan dengan kejadian anemia karena responden yang kunjungan ANC nya kurang dari 3 selama masa kehamilan, 12 responden mengalami anemia yaitu 7 responden anemia ringan, 1 responden anemia sedang dan 4 responden mengalami anemia berat. Sedangkan responden yang kunjungan ANC nya lebih dari 4 kali, 44 responden mengalami anemia yaitu 31 responden anemia ringan, 11 responden anemia sedang dan 2 responden anemia berat.

\section{DAFTAR PUSTAKA}

Armaya, Rita. 2018. Kepatuhan Ibu Hamil dalam Melakukan Kunjungan Antenatal Care dan Faktor yang Mempengaruhi. Jurnal Kesehatan Masyarakat. Vol. 07 (01).

Dinas Kesehatan Kabupaten Sukoharjo. 2013. Profil Kesehatan Sukoharjo. DinKes, Sukoharjo.

Hendrayani, M.D., Anak Sagung Agung Sawitri dan Mangku Karmaya. 2013. Perilaku Pemeriksaan Antenatal sebagai Faktor Risiko Anemia Gizi Ibu Hamil di Puskesmas II Denpasar Selatan Tahun 2012. Public Health and Preventive Medicine Archive, Volume 1, Nomor 1. Diunduh pada tanggal 22 Desember 2018.

Hutahaean, S. 2013. Perawatan Antenatal. Salemba Medika, Jakarta.

Kementerian Kesehatan RI. 2013. Profil kesehatan Indonesia. Kemenkes, Jakarta.

Kumalasari, Intan. 2015. Panduan Praktik Laboratorium dan Klinik Perawatan Antenatal, Intranatal, Postnatal, Bayi
Baru Lahir, dan Kontrasepsi. Salemba Medika, Jakarta.

Leveno, K. J., ed. 2016. Manual Williams Komplikasi Kehamilan. Alih bahasa Ong, Herman Octavius, et al. Buku Kedokteran EGC, Jakarta.

Purwandari, A., F. Lumy dan F. Polak. 2016. Faktor-Faktor yang berhubungan dengan Kejadian Anemia. Jurnal Ilmiah Bidan. Vol. 4 (1). Diunduh pada tanggal 2 November 2018.

Shitie, D., Tewabech Zewde dan Yalew Molla. 2018. Anemia and Other Hematological Profiles of Pregnant Woman Attending Antenatal Care in Debre Berhan Referral Hospital, North Shoa, Ethiopia. BMC Research Note.http:/doi.org/10.1186/s13 104-018-3805-8.

Varney, H., Jan M. Kriebs, dan C. L. Gregor. 2007. Buku Ajar Asuhan Kebidanan. Alih bahasa Ana Lusiyana. Buku Kedokteran EGC, Jakarta.

Wagiyo dan Putrono. 2016. Asuhan Keperawatan Antenatal, Intranatal dan Bayi Baru Lahir. CV Andi Offset, Yogyakarta.

Walyani, E. Siwi dan E. Purwoastuti. 2015. Konsep dan Asuhan Kebidanan Maternal Dan Neonatal. Pustaka Baru Press, Yogyakarta.

Wibowo dan Wisnuwijoyo. 2014 Survei Cepat : Karakteristik dan Prevalensi Anemia Ibu Hamil Di Kabupaten Sukoharjo Tahun 2011. Mandala of Health, Volume 7, Nomor 3. Diunduh pada tanggal 2 November 2018.

${ }^{1}$ Dosen Akper Panti Kosala

Surakarta

${ }^{2}$ Mahasiswa Akper Panti Kosala

Surakarta 